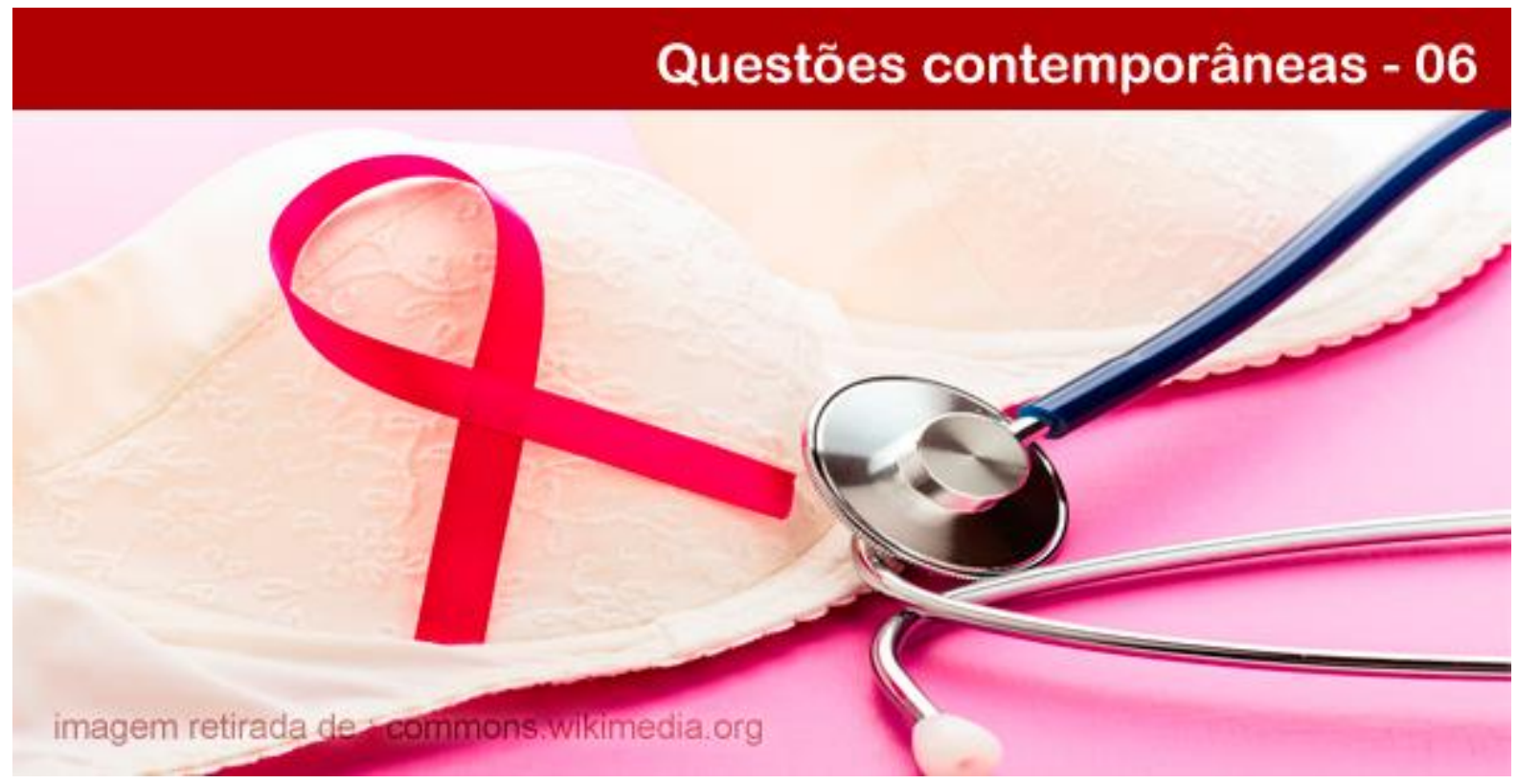

\title{
REPRESENTAÇÕES SOCIAIS DO TRATAMENTO QUIMIOTERÁPICO CONSTRUÍDAS POR MULHERES ACOMETIDAS PELO CÂNCER DE MAMA: ESTUDO DE OBSERVAÇÃO EM UM AMBIENTE HOSPITALAR
}

\section{Verônica Braga dos Santos}

Doutoranda do Programa de Pós-graduação em Psicologia Social da Universidade do Estado do Rio de Janeiro (UERJ). Mestre em Saúde Coletiva pela Universidade Federal do Rio de Janeiro (UFRJ). Graduação em Curso de Formação de Psicólogo pela UFRJ. E-mail: verosbraga@gmail.com.

\section{Ricardo Vieiralves de Castro}

Pós-doutorando em História Social pela Universidade de São Paulo (USP). Doutorado em Comunicação pela Universidade Federal do Rio de Janeiro (UFRJ). Mestrado em Psicologia Clínica pela Pontifícia Universidade Católica do Rio de Janeiro (PUC/RJ). Graduação em Psicologia (licenciatura e bacharelado) pela Universidade do Estado do Rio de Janeiro (UERJ). Professor Associado da Universidade do Estado do Rio de Janeiro.

Resumo: O tratamento quimioterápico é uma das opções terapêuticas para uma doença de magnitude epidemiológica e de significado histórico associado à morte, culpa, medo. Possivelmente a terapêutica quimioterápica entra no circuito de construções sociais de significados acerca dessa doença para além dos espaços especializados. Com base na Teoria das Representações Sociais (TRS) objetivou-se identificar e analisar as representações sociais sobre o tratamento quimioterápico construídas por mulheres brasileiras acometidas pelo câncer de mama, matriculadas no Instituto Nacional de Câncer José Alencar Gomes da Silva (INCA). A TRS permite a compreensão das interpretações e dos sentidos que os grupos e sujeitos têm sobre objetos sociais para eles relevantes. $\mathrm{O}$ artigo apresenta os dados oriundos da observação realizada no setor de quimioterapia no hospital de tratamento para o câncer de mama do INCA. O material coletado foi analisado a partir de seu conteúdo e separado em categorias temáticas. Foram nomeadas três principais categorias: Aspectos organizacionais e técnicos sobre o tratamento quimioterápico; Interações entre atores no contexto da doença e do tratamento; Dor, sofrimento, morte. O tratamento quimioterápico apresenta-se dividido entre quimioterapia vermelha e branca, e em cada uma delas se explica as características de efeitos colaterais. Com isso, distancia-se de um grupo complexo de significações trazendo para perto como algo mais concreto, o que se visualiza no frasco e o que se sente no organismo. A familiarização é uma estratégia para essas mulheres lidarem com algo tão ameaçador, como o câncer e o tratamento quimioterápico, que podem estabelecer descontinuidades da rotina, das relações sociais e da própria existência.

\section{POLÊM!CA $\mid$ LABORE (s:}

Polêmica - Revista Eletrônica da Uerj - Rua São Francisco Xavier, 524, $1^{\circ}$ andar

bloco D, sl.1001 • Tels.: +55 21 2334-4088/4087 • http://www.e-publicacoes.uerj.br/index.php/polemica/index http://www.labore.uerj.br • laboreuerj@yahoo.com.br 
Palavras-chaves: Neoplasias da mama. Quimioterapia. Representações sociais.

\title{
SOCIAL REPRESENTATIONS OF CHEMOTHERAPY TREATMENT BUILD BY WOMEN SUFFERING FROM BREAST CANCER: A STUDY OF OBSERVATION IN THE HOSPITAL ENVIRONMENT
}

\begin{abstract}
The chemotherapy treatment is a therapeutic option for a disease of epidemiological magnitude and historic meaning associated to death, blame, fear. The chemotherapy treatment is possibly part of the social constructions of meanings around this disease and its repercussions far beyond the specialized venues. Based upon the Social Representations Theory (SRT), this research aims to identify and analyze the social representations of chemotherapy treatment built by Brazilian women with breast cancer, patients at INCA. SRT allows to understand interpretations and meanings that groups and subjects have of social objects which are relevant to them. The article presents data derived from observation in the chemotherapy section of INCA's breast cancer treatment hospital. The data collected was submitted to thematic categorical content analysis and thus three main thematic categories were named: organizational and technical aspects about chemotherapy treatment; interactions among actors in the context of the disease and the treatment; and pain, suffering, death. Chemotherapy treatment is divided into red chemo and white chemo, and in each one of them the characteristics of side effects are explained. Thus one is distanced from a complex group of meanings, bringing closer what is seen in the bottle and felt in the body as something more concrete. Familiarization is a strategy for these women to deal with something so threatening as cancer and chemotherapy, which can discontinue one's routine, social relations and even existence.
\end{abstract}

Keywords: Breast neoplasm. Chemotherapy. Social representations.

\section{Introdução}

De acordo com o Ministério da Saúde (BRASIL, 2011b), o câncer é uma das quatro principais doenças crônicas não transmissíveis (DCNT) causadoras de morte no mundo. Dentre seus tipos, o câncer de mama destaca-se como o de maior incidência e o de maior mortalidade entre as mulheres tanto em países desenvolvidos como nos em desenvolvimento. A estimativa para o Brasil, em 2016-2017, é de ser o tipo de câncer mais frequente entre as mulheres, excetuando a contagem do câncer de pele não melanoma (INCA, 2015).

Na prática do atendimento psicológico às mulheres acometidas pelo câncer de mama, durante a Residência Multiprofissional em Oncologia no Instituto Nacional de Câncer José Alencar Gomes da Silva (INCA), observou-se a recorrência de uma forma de expressão do ‘impacto' emocional diante do diagnóstico de câncer. Verbaliza-se muitas vezes a doença como algo que faz 'abrir, tirar o chão' ou faz 'o mundo desabar nas costas'.

Estudos acerca dos significados sobre o câncer construídos socialmente indicam ainda uma associação do câncer à culpa, à estigmatização social, à provação e ao castigo. Por sua vez, o diagnóstico de câncer é vivenciado com impacto e desespero por remeter à morte, à doença incurável, à dor e à certeza da alteração da imagem corporal. Surgem o medo, a tristeza, a angústia e a frustração não só diante do diagnóstico, mas também ao longo do período dos tratamentos (ARÁN et al., 1996; FERREIRA; ALMEIDA; RASERA, 2008;

\section{POLÊM!CA $\mid$ LABORE}

Polêmica - Revista Eletrônica da Uerj - Rua São Francisco Xavier, 524, $1^{\circ}$ andar

bloco D, sl.1001 • Tels.: +55 21 2334-4088/4087 • http://www.e-publicacoes.uerj.br/index.php/polemica/index http://www.labore.uerj.br • laboreuerj@yahoo.com.br 
FUNGHETTO; TERRA; WOLFF, 2003; MISTURA; CARVALHO; SANTOS, 2011; SOUZA; GOMES, 2012; TAVARES; TRAD, 2005; ZAGO; MONTES, 2005).

A notícia da necessidade do tratamento quimioterápico, assim como o diagnóstico de câncer, pode ser vivenciada com tristeza, choro e medo dos efeitos colaterais que a terapêutica pode provocar (CONCEIÇÃO; LOPES, 2008; SALES et al., 2003; SOUZA; SANTO, 2008). Uma das preocupações são os efeitos tóxicos que levam aos incômodos físicos (como náuseas, vômitos, fadiga) e consequentes alterações alimentares, estéticas, sociais, laborativas e emocionais.

$\mathrm{Na}$ experiência da escuta clínica no INCA, a possibilidade do tratamento quimioterápico se destacava na fala das mulheres mesmo em um período que muito se antecipava a qualquer deliberação. Contudo, desde esse momento, são expressos expectativas, o pavor e o medo desse tratamento. Surgem preocupações e apreensões acerca dos possíveis resultados (a expectativa e incerteza de cura, assim como de viabilidade cirúrgica) e dos seus efeitos colaterais. Dentre esses, as mudanças na imagem corporal (ex.: alopecia) e alterações funcionais do organismo (náuseas, vômitos), assim como interrupção das atividades de trabalho e sociais.

Diante das apreensões apresentadas por mulheres quanto ao tratamento quimioterápico e por ser uma das opções terapêuticas para uma doença com magnitude epidemiológica, possivelmente esse tratamento entra no circuito de construções sociais de significações acerca dessa doença, e de suas repercussões, para além dos espaços especializados.

\section{Objetivo}

Identificar e analisar, a partir de uma leitura com base na Teoria das Representações Sociais, as representações sociais sobre o tratamento quimioterápico construídas por mulheres brasileiras acometidas pelo câncer de mama, em tratamento no Instituto Nacional de Câncer José Alencar Gomes da Silva (INCA).

\section{Fundamentação teórica}

Optou-se pela Teoria das Representações Sociais (TRS), uma teoria psicossociológica do conhecimento, elaborada por Serge Moscovici (2007), por ela permitir a compreensão das

\section{POLÊM!CA $\mid$ LABORE}


interpretações e dos sentidos que os grupos e sujeitos têm sobre objetos sociais para eles relevantes.

Compreender as representações sociais diz respeito a entender como um determinado grupo elabora concepções, práticas e articulam saberes sobre determinado objeto (material ou não) que seja relevante para ele. Propõe-se conceber os saberes como sociais e entender como são construídos com referência ao seu contexto de inserção, apresentados e reapresentados de forma não só a estabelecer, mas, também, a manter a comunicação e interações.

\section{Metodologia}

O presente artigo é a apresentação de uma parte da pesquisa realizada e apresentada como tese para obtenção do título de Doutorado, no Programa de Pós-graduação em Psicologia Social da Universidade do Estado do Rio de Janeiro (UERJ). Foram realizadas duas formas de coleta de dados: observação e entrevistas. Serão expostos a metodologia e os resultados referentes ao processo da observação.

Propôs-se identificar a organização, as regras e normas, assim como o esquema da constituição social e os aspectos da cultura em que as mulheres estão inseridas ao longo do tratamento. Para isso foram descritos e anotados os fenômenos observados dentro do ambiente hospitalar. Da mesma forma, um segundo aspecto observado foram os detalhes da interação e padrões de comportamentos interpessoais. E um terceiro, foram os modos de pensar e sentir dos atores presentes na instituição, de acordo com sua cultura. Na pesquisa, esses atores foram as mulheres em tratamento quimioterápico. Com esse fim, foram registradas suas opiniões, expressões e narrativas características. Foi utilizado um diário etnográfico, instrumento onde foram registrados todos os aspectos acima enumerados, decorrentes das observações do campo (MALINOWSKI, 1976).

Os ambientes principais nos quais a pesquisadora esteve presente para observação foram a sala de espera e o salão de aplicação de quimioterapia, na Central de Quimioterapia do Hospital do Câncer III (HCIII), unidade de tratamento do câncer de mama, do INCA.

O projeto foi submetido para avaliação e aprovado na Comissão de Ética em Pesquisa da UERJ (Coep - UERJ), por ter sido a instituição proponente, e no Comitê de Ética em Pesquisa do INCA (CEP - INCA), instituição coparticipante, o cenário da pesquisa.

\section{POLÊM!CA $\mid$ LABORE}




\section{Resultados}

A observação na Central de Quimioterapia do HCIII, para tratamento do câncer de mama, foi realizada entre os meses de julho e dezembro do ano de 2015, concluindo aproximadamente 15 horas de observação. Incluiu conversas com profissionais do setor, observação na sala de espera e no salão de aplicação da quimioterapia. Foi possível também acompanhar duas consultas da enfermagem específicas para pacientes de primeira vez no tratamento quimioterápico. Após cada observação, que durava cerca de uma hora, e conversa com os profissionais, as informações eram anotadas em um diário de campo o mais fielmente possível, de acordo com as palavras e expressões utilizadas. O material coletado foi analisado a partir de seu conteúdo e separado em categorias temáticas (BARDIN, 2003). Foram nomeadas três principais categorias: Aspectos organizacionais e técnicos sobre o tratamento quimioterápico; Interações entre atores no contexto da doença e do tratamento; Dor, sofrimento, morte.

Aspectos organizacionais e técnicos sobre o tratamento quimioterápico

A presente categoria foi organizada em três subcategorias: Conhecimento e informações técnicas sobre os tratamentos e sobre os cuidados; Efeitos adversos do tratamento quimioterápico; Aspectos organizacionais da sala de espera e do salão de aplicação da quimioterapia.

Os "Conhecimentos e as informações técnicas sobre os tratamentos e sobre os cuidados" foram observados de acordo tanto com os profissionais, quanto com as pacientes e os acompanhantes.

Segundo a literatura, o tratamento quimioterápico pode ser indicado em diferentes momentos do percurso terapêutico, a depender do estadiamento da doença, isto é, da extensão anatômica do tumor e da presença ou não de metástase (BONASSA; GATO, 2012). Desse modo, existem protocolos com medicamentos e frequências de aplicações adequados a cada estadiamento e segundo a sua finalidade: neoadjuvante, adjuvante ou paliativa.

A quimioterapia neoadjuvante objetiva reduzir o tumor loco-regionalmente avançado, com vistas à realização de uma cirurgia potencialmente curativa ou que auxiliará na melhora do prognóstico do doente (BRASIL, 2011a; SBOC, 2011). A quimioterapia adjuvante, por sua vez, ocorre após a cirurgia e trata possíveis micrometástases; objetiva diminuir o risco de

\section{POLÊM!CA $\mid$ LABORE}


recidiva, aumentar o intervalo do tempo livre de doença e da sobrevida global. E o tratamento quimioterápico paliativo visa ao controle de sinais e sintomas que a doença provoca e que interferem na capacidade funcional do doente, assim como à redução e controle de tumores metastáticos ou da recidiva local da doença (BRASIL, 2011a; SBOC, 2011).

A observação no setor de quimioterapia coletou dados sobre o conteúdo dos diálogos, expressões, convivência e interação entre pacientes que apresentavam distintos estádios da doença e protocolos de tratamento quimioterápico. No entanto, a coleta de dados aprofundouse sobre as informações técnicas do tratamento quimioterápico neoadjuvante e adjuvante.

De acordo com os profissionais e com as informações obtidas no processo da observação, a quimioterapia neoadjuvante ou adjuvante para o câncer de mama segue um protocolo de um total de oito ciclos (ou aplicações) em intervalos de 21 em 21 dias (no máximo 28 dias). Os oito ciclos correspondem a quatro ciclos dos medicamentos Adriamicina e Ciclofosfamida (AC) com mais quatro ciclos de Taxotere (TXT). Quando o tipo de câncer apresenta o receptor Her2 positivo, há acréscimo de um medicamento não quimioterápico, o Herceptin $^{1}$ (Trastuzumab), um anticorpo monoclonal aplicado em 17 ciclos com intervalos de 21 dias. Esses ciclos iniciam-se juntamente ao TXT. Assim, essas mulheres fazem 4 ciclos de AC, 4 ciclos de TXT junto com Herceptin e mais 13 ciclos somente de Herceptin. No caso das mulheres que realizam a neoadjuvância, os 13 ciclos restantes de Herceptin são administrados após a recuperação da cirurgia.

Os quimioterápicos são administrados por via intravenosa, de forma direta puncionando uma veia com uma agulha, preferencialmente do antebraço ou, se não for possível, do dorso da mão. Outro meio é por um cateter (tubo fino inserido na veia). Os remédios podem ser aplicados dentro de um soro ou como injeções diretamente no acesso feito na veia (INCA, 2013). Cada ciclo de quimioterapia segue um esquema que inclui remédios chamados pré-quimioterápicos (pré QT), isto é, que pretendem preparar o corpo para receber os quimioterápicos. O objetivo é evitar enjoos, alergias e anafilaxia, assim como danos ao estômago. A pré QT do ciclo de AC inclui Dexametasona e Ondansetrona e a pré QT do ciclo de TXT é composta por Dexametasona, Ondansetrona, Difenidramina e Ranitidina. O esquema de aplicação de AC dura entorno de $1 \mathrm{~h} 30$ min e o de TXT cerca de $2 \mathrm{~h}$.

\footnotetext{
1"Herceptin é um anticorpo monoclonal indicado para mulheres que apresentam a amplificação cromossômica de um fragmento de DNA, que contém o Gene HER 2 (gene fator2 de crescimento epidermóide humano), no próprio tumor e no sangue (INCA, 2008, p.463).
}

\section{POLÊM!CA $\mid$ LABORE}


Para realizar o tratamento quimioterápico, as mulheres são atendidas pelo médico oncologista, quem avalia a necessidade ou não desse tratamento e quem prescreve os medicamentos e suas dosagens de acordo com o protocolo adequado a cada caso. A rotina do tratamento inclui consultas de acompanhamento com o oncologista que antecede as aplicações dos quimioterápicos. É realizada uma avaliação com exame de sangue, por exemplo, a fim de verificar se a paciente está em condições físicas de realizar uma ou mais aplicações subsequentes, de acordo com o protocolo.

Além do atendimento médico, as pacientes realizam consultas de orientações e cuidados específicos quanto ao tratamento quimioterápico com a enfermagem e com a nutrição. Elas recebem uma cartilha elaborada pelo INCA sobre a quimioterapia e sobre algumas orientações aos pacientes. No primeiro dia do tratamento quimioterápico para o câncer de mama, antes de iniciar a aplicação, as pacientes são sempre atendidas pela enfermagem em uma consulta individual. Foram observadas duas consultas da enfermagem em que foram dadas informações sobre os medicamentos, as reações adversas possíveis e sobre os cuidados necessários ao longo da terapêutica.

De acordo com as pacientes e com os acompanhantes, houve descrição sobre procedimentos e etapas do tratamento. No salão de aplicação dos quimioterápicos e na sala de espera, onde ficam acompanhantes e pacientes, foram observadas conversas em que seus conteúdos abordavam os aspectos técnicos e de organização da quimioterapia. As pacientes descreviam uma para as outras em qual ciclo estavam do tratamento, explicavam a quantidade e a duração das aplicações dos remédios, por vezes nomeando-os.

Quando explicitavam os medicamentos, os designavam como "a vermelha", "a branca" e "Herceptin". Ou mesmo como "Hercepse". A nomeação dos quimioterápicos da neoadjuvância e da adjuvância ocorria pelo uso dos termos "a vermelha" e "a branca", que correspondem, respectivamente, ao AC e ao TXT. Usam essa terminologia para comentar e compartilhar qualquer aspecto sobre os remédios. Ex: "essa é a quarta da vermelha"; "na branca sentia cansaço". Apropriam-se de termo médico, como imunidade, e explicam sua variação durante o período da quimioterapia: "entre os dias 7 e 14 a imunidade sobe".

Pacientes e acompanhantes mencionaram ainda concepções sobre resultados da quimioterapia, confirmando o que esperavam da sua ação: diminuir o tumor (quando proposta neoadjuvante ou paliativa). Relataram perceber a redução do tumor em seus corpos ou no da

\section{POLÊM!CA $\mid$ LABORE}


paciente (segundo uma acompanhante). Segundo enfermeiras, há pacientes que se preocupam se a quimioterapia está fazendo efeito quando não acontece uma reação esperada, como ardência no nariz durante a infusão de um dos medicamentos ou quando o cabelo volta a crescer no intervalo entre os ciclos.

Outro tema abordado por pacientes em seus diálogos é sobre cuidados durante o tratamento quimioterápico, o que pode ou não fazer e as consequentes mudanças na rotina. Por exemplo, não poder ficar exposto ao sol e, principalmente, no que diz respeito à alimentação: acréscimo de frutas, não ingestão de peixe cru e de frituras, não consumir refrigerantes e bebida alcóolica. Há, no entanto, uma variação desses comportamentos entre as pacientes. Enquanto uma diz que segue a dieta indicada, a outra nega seguir a dieta e que a dificuldade está em não sentir o gosto da comida. Referem ainda uma escolha sobre o que se evita ou o que se acrescenta. Uma paciente evita peixe cru, mas não os alimentos gordurosos. Resolve acrescentar fígado devido a anemia, mas explica que dependendo de como está a imunidade, se não estiver baixa, pode-se ingerir bebida alcóolica.

A subcategoria "Efeitos adversos do tratamento quimioterápico" aborda os sintomas manifestos ao longo do período do tratamento e os sintomas durante a aplicação dos quimioterápicos. Os efeitos adversos do tratamento é um assunto que surgia quando as enfermeiras, após a punção da veia, perguntavam às pacientes como estavam e como tinham passado após o último ciclo ou surgia de forma espontânea durante as conversas entre as pacientes.

O enjoo foi afirmado por uma paciente após o segundo ciclo de AC, no entanto, outras quatro negaram a manifestação desse sintoma; uma delas explica que é devido ao uso contínuo do remédio para evitar a náusea. Três pacientes relatam que não sentiram sintoma algum após a última aplicação.

Os sintomas descritos associados à quimioterapia foram: cansaço, queda do cabelo, mudança de cor das unhas ("amarelaram"), febre, prisão de ventre, ressecamento da pele, aumento de peso, alteração do humor (irritação, choro), alteração da memória e do pensamento (bloqueio), alterações no paladar (não sentir gosto da comida) e no olfato.

$\mathrm{O}$ aumento de peso foi explicado por uma paciente como consequência de um dos remédios do preparo, a Dexametasona:

\section{POLÊM!CA $\mid$ LABORE}


Paciente 2: "O inchaço é da Dexa". [Diz que ficou muito inchada, faz movimento com as mãos para mostrar como estava o tamanho do seu corpo.]

Paciente 1: “Ah, então esse inchaço é da Dexa. E volta tudo, então, como era antes?" (Diário de campo).

A paciente 2 diz que sim, mostrando que emagreceu bem. Diz que uma coisa que presta atenção é na alimentação: "Faço direitinho dieta".

A alteração no olfato foi um tema no diálogo entre três mulheres e que trouxe mudanças de hábitos e na rotina da casa junto aos familiares. "O olfato ficou extremamente apurado". Os 'cheiros' que passaram a ser percebidos como ruins ou a incomodar foram de perfume, de produto de limpeza, de creme para o corpo, de fritura e de refrigerante. Uma delas relata que precisa ficar no quarto enquanto a filha faz comida, principalmente com fritura, que seus familiares só podem aplicar o perfume em outro cômodo da casa e que a vida deles em família mudou, perguntam, por exemplo, o que podem ou não fazer dentro de casa.

O outro 'cheiro' importante que mencionam é o odor do próprio corpo. Explicam que sentiam um cheiro desagradável, pensavam que podia ser de alguma sujeira da casa, mas perceberam que vinha do próprio corpo: "Era eu mesma". Uma descreve como um cheiro de percevejo e a outra explica relacionando à excreção da quimioterapia: "É, tem que sair por algum lugar. Sai pela urina, pelas fezes, pelo suor”. Esse cheiro é relatado com grande incômodo e junto com a alteração do olfato podem interferir na sensação de bem-estar, também, na intimidade com o companheiro: "Não dá pra usar perfume, um creme, não dá nem pra usar para dar uma ajudinha.".

Quanto aos sintomas durante a aplicação dos quimioterápicos, esses podem provocar reações adversas que se manifestam durante a própria aplicação; são reações alérgicas ou podem até serem anafiláticas. Essas reações foram relatadas pelas pacientes ou presenciadas durante a observação. Descreveram como rubor na face, formigamento na mão, boca seca, lágrimas nos olhos, coceira na garganta, tosse, sensação de garganta fechando e ardência na face perto do nariz. Essa é esperada ao final de um dos medicamentos do ciclo de AC. Uma paciente apresentou duas reações associadas ao Herceptin: tremedeira e aumento da temperatura. Além de ser possível, também, dor nas costas.

Quando essas reações acontecem, o procedimento é chamar um médico para avaliar e passar algum medicamento se necessário, assim como parar a infusão até haver melhora do quadro. Uma enfermeira sugere a elaboração de um protocolo com as orientações e

\section{POLÊM!CA $\mid$ LABORE}


medicamentos para essas reações, de forma que elas mesmas pudessem socorrer a paciente rapidamente.

A observação incluiu os "Aspectos organizacionais da sala de espera e do salão de aplicação da quimioterapia”. A Central de Quimioterapia funciona das $7 \mathrm{~h}$ às $19 \mathrm{~h}$, de segundafeira a sábado, e comporta profissionais da enfermagem, técnicos de enfermagem, técnicos administrativos e funcionários da limpeza. $\mathrm{O}$ espaço físico é organizado com uma sala de espera, a partir da qual se têm acesso a três salas de atendimento da enfermagem e ao salão de aplicação dos quimioterápicos. Contíguo ao salão, há o setor da farmácia, onde são manipulados e preparados os medicamentos de cada paciente no dia da aplicação.

Na sala de espera há duas secretárias na recepção, há cadeiras, uma geladeira pequena com suco e sanduíches para as mulheres em tratamento, água, um quadro de aviso e de mensagens (de agradecimento, de incentivo, de cunho espiritual ou divulgação de alguma informação pelo próprio público), revistas e uma televisão. No salão de aplicação da quimioterapia, há 12 lugares para as pacientes: 10 poltronas, uma maca e uma cadeira de rodas. Os assentos ficam no entorno do salão e no centro há uma mesa comprida, utilizada pelos profissionais e a partir da qual é possível ter uma visão de todo o salão. Há música ambiente e televisões.

Observou-se na sala de espera um grande incômodo com o tempo em que se aguarda para começar a aplicação dos remédios. Cada paciente tem um horário marcado, porém, na prática, há uma espera que pode durar de $1 \mathrm{~h}$ a $3 \mathrm{~h}$ ou mais para iniciar o tratamento. Pacientes e acompanhantes manifestam incômodo nessa situação: reclamam entre si sobre a demora, comentam a hora em que estava marcada a aplicação, se dirigem às enfermeiras no salão para perguntar se já serão chamadas explicando o tempo que estão aguardando e comentam com as secretárias. Algumas pessoas utilizam do humor para expressar a insatisfação: "Esqueceram de mim 5". "Esqueceram de mim 4, 5, 6, 7, 8, 9, 10."

Os motivos dos atrasos podem ser variados, explica uma enfermeira. Há diferentes circunstâncias que somadas levam ao tempo prolongado da espera. No entanto, são os profissionais da enfermagem que estão em contato direto com o público do setor e são pressionados. Somam-se o horário de espera ao tempo de duração das infusões, quase um dia todo ou uma manhã ou tarde inteira no hospital. Uma paciente utiliza uma expressão ao se despedir de outra: estava deixando o "chá de hospital".

\section{POLÊM!CA $\mid$ LABORÉ}


$\underline{\text { Interações entre atores no contexto da doença e do tratamento }}$

A categoria "Interações entre atores no contexto da doença e do tratamento" diz respeito às relações interpessoais entre profissionais, pacientes, familiares, acompanhantes e a sociedade com as pessoas em tratamento para o câncer.

Nas interações entre pacientes, na Central de Quimioterapia, observou-se a troca de informações e dicas sobre alguns materiais que podem ser usados diante das alterações físicas e dos efeitos colaterais provocados pelo tratamento quimioterápico ou pela cirurgia: sobre peruca, bojo para sutiã ou indicação de creme para o ressecamento da pele.

Além disso, as pacientes apresentaram iniciativa com comportamentos de cuidado, carinho ou consolo entre elas, observados na Central de Quimioterapia. Exemplifica-se com a oferta de suco para outras pacientes da sala de espera, quando uma paciente foi se servir: "Vamos tomar um suquinho? Para crescer?", e com a expressão de consolo por meio de abraço, beijo, apoio da cabeça no ombro ou com palavras. Ex.: uma paciente descrevia uma situação em que estava passando no tratamento quimioterápico para uma enfermeira e depois para o enfermeiro que fazia a punção para aplicação dos quimioterápicos, chora e, quando a paciente ao lado - que escutou e observou a cena - levanta para ir embora, vai até a outra paciente, a abraça, beija e fala algo. Na sala de espera, uma paciente conforta outra que parecia triste e com lágrimas, abraçando-a, apoiando sua cabeça em seu ombro e mencionando palavras de consolo.

No que diz respeito às interações entre pacientes e acompanhantes no hospital, pode-se afirmar que os acompanhantes, familiares ou não, são pessoas integrantes do processo de tratamento das pacientes. Alguns estão presentes pontualmente nas idas ao hospital ou nos cuidados em casa, ou podem ser os principais cuidadores: mãe, filha, filho, companheiros (as), outros familiares, vizinhas, amigas. Na sala de espera do setor da quimioterapia, conversam com outras pacientes ou com outros acompanhantes.

Observou-se alguns comportamentos dos acompanhantes junto às pacientes. Eles assumem funções: resolutivas, como enquanto aguardam a paciente ser atendida ou terminar a aplicação dos medicamentos, se dirigem ao setor de marcação de consultas para marcar consultas ou exames das pacientes no hospital; de cuidados, ao ajudar a ir ao banheiro durante a aplicação, pois as pacientes ficam com uma mão limitada quando estão com o acesso, ou

\section{POLÊM!CA $\mid$ LABORE}


ajudam a sair da sala de aplicação quando termina (principalmente as mais idosas), ou com um cuidado específico, como um companheiro ao levar mais papel toalha para a esposa que salivava e limpava a boca a todo momento. Uma acompanhante, mãe, expressa sua preocupação em se certificar que sua filha ficará bem cuidada antes de sair do salão de aplicação, dirigindo-se à enfermeira que estava com a paciente: "cuida bem da minha bebê, tá? Da minha bebezinha [risos]". Outros comportamentos foram cenas em que se expressava gestos de carinho com as pacientes.

Outra forma de interação presente no hospital é entre profissionais e pacientes. Um dos aspectos da relação entre os profissionais e as pacientes é a função daqueles de transmitir orientações e informações quanto ao tratamento quimioterápico. Há o momento dedicado a isso, que é o das consultas de enfermagem quando se inicia essa terapêutica e quando se inicia os quatro últimos ciclos com a mudança de medicamento (a quimioterapia "branca"). No entanto, essa troca entre profissionais e pacientes acontece no contato constante durante o tratamento. Esclarecimentos da enfermagem são reforçados no salão de aplicação durante as interações. Por exemplo, quando se realiza a punção e se encontra alguma dificuldade, as enfermeiras explicam o exercício a ser feito com uma bolinha, com o objetivo de fortalecer as veias.

Um aspecto observado é o uso do humor pelos profissionais como uma forma de lidar com o tratamento e com suas possíveis intercorrências. Uma interpretação do tratamento como algo que causa danos pode estar manifesta na fala de uma profissional. Por exemplo, uma enfermeira dirige-se à paciente e pergunta: "Vamos pra próxima? Pra próxima vítima? [risos]. Agora vai começar a ciclo [ciclofosfamida], tá?” - diz para a paciente que iria começar o próximo remédio.

O humor apresentou-se em situações da punção, que demandam concentração, habilidade técnica do profissional e condições favoráveis das veias, além de ser um momento de apreensão para as pacientes. Outra situação que pode causar estresse e que demanda ação resolutiva rápida é a avaliação dos sintomas, a solicitação da presença de um médico e o atendimento das pacientes que manifestam reações alérgicas ou anafiláticas durante a infusão. O humor se apresenta após o momento mais crítico.

$\mathrm{Na}$ relação entre os profissionais enfermeiros e as pacientes há a manifestação do cuidado, observada a partir do discurso e por meio de gestos. Observa-se em diferentes

\section{POLÊM!CA $\mid$ LABORE}


ocasiões a preocupação com algum dano à paciente diante da dificuldade de puncionar uma veia - um profissional pede ou recebe ajuda de outro para realizar esse procedimento após tentativas sem sucesso. Em outros momentos, o cuidado se apresenta quando se utilizam da percepção das expressões da paciente e de uma leitura de seu estado emocional com auxílio de suas experiências anteriores, de forma a guiar sua conduta no atendimento.

Há cenas em que se demonstra a existência de vínculo entre as pacientes e profissionais da enfermagem. O tempo de convivência no hospital durante o tratamento é longo e os profissionais de enfermagem, por exemplo, no período da observação, eram na maioria os mesmos e se revezavam em escala diária entre salão de aplicação e as salas de consulta dentro da Central de Quimioterapia. Houve retorno de pacientes ao salão de aplicação somente para rever os profissionais e conversar com as enfermeiras, relatar como estão, bem ou não. Ao longo do tratamento há também essa referência. Por exemplo, uma paciente ao ser chamada para o salão, se dirige a uma das enfermeiras, a trata pelo seu nome, e, antes de se sentar, explana a situação difícil que passa no tratamento, com expressão de tristeza. A enfermeira diz para ela ficar bem, não desistir. A paciente também conversa com o enfermeiro que realiza a punção, chora e este a acalenta com palavras para ela ficar tranquila.

Outras interações existentes são entre as pacientes e os familiares ou companheiro. A presença dos familiares durante o tratamento do câncer de mama pode ser vivenciada de formas diferentes de acordo com a relação existente. Para uma paciente, a presença da mãe lhe causa incômodo e prefere seu afastamento. Relata que a mãe brigou com seu marido porque queria acompanhá-la no hospital, mas a paciente não deixou: "A minha mãe me estressa tanto, tanto, tanto. (...) Eu evito ficar perto”. Diz que ela é muito nervosa e que ficaria nervosa com ela, "ela não faz por mal, é mãe". O apoio e presença do marido e do filho foram mencionadas como importantes por outra paciente que, ao falar sobre o diagnóstico, relata: "nessas horas sabemos quem são os verdadeiros amigos".

A relação entre as mulheres com a doença e os companheiros foi comentada por duas enfermeiras como uma relação que seria testada ou entraria em colapso com o adoecimento da mulher: “Ah! Então, o marido é bom. Se for ruim, agora é a hora [de terminar]!” - uma enfermeira comenta com uma paciente que falava sobre seu marido. A outra profissional explica para a pesquisadora sobre a não assumpção do papel de cuidado pelos homens e por

\section{POLÊM!CA $\mid$ LABORÉ}


mudanças no corpo feminino causadas pelo tratamento, que alterariam a relação na sexualidade:

\footnotetext{
"São poucos os companheiros que acompanham, que ajudam. (...) Quando é uma mulher com câncer, muitos homens tem uma mulher fora ou saem de casa, mas, se é o homem com câncer, a mulher não abandona. (...) A mulher tem a questão da alteração da imagem e o seio é importante para muitas e para os homens. Aí os homens cuidarem dos filhos...". (Diário de campo).
}

Outra interação que pode ser explicitada é entre sociedade e pessoas com câncer e em tratamento para o câncer. Pacientes relatam a expectativa das pessoas de que certamente algum efeito adverso do tratamento acontecerá ou o teor de relatos ruins (provavelmente escutados no hospital) sobre esses efeitos e expressam o seu incômodo diante dessas situações.

A visão da sociedade sobre o acometimento do câncer e seus tratamentos se expressa, também, no conteúdo e na forma adotados em eventos como do Outubro Rosa de 2015, no hospital. A beleza e a autoestima das pacientes foram temas abordados em palestras e oficinas de beleza. Na prática, ensinou-se nas oficinas como se maquiar e opções de amarrações de lenços, além disso, em diferentes espaços da unidade hospitalar havia mesas em que voluntários maquiavam as pacientes. Maquiadores foram ao salão de aplicação da quimioterapia e ofereciam às mulheres a pintura e aplicação de henna nas sobrancelhas. A produção da beleza foi tratada como forma de estimular a autoestima, partindo-se da ideia, então, de que esta pode ser abalada com o acometimento da doença e as transformações do corpo.

No mesmo evento, houve um grupo com violão que foi ao setor de quimioterapia cantar para as pacientes. O conteúdo das músicas escolhidas pode expressar o que se representa sobre ter um câncer e passar por seus tratamentos. A maioria das pacientes e acompanhantes na espera participaram cantando, algumas se emocionaram, assim como no salão de aplicação. Entre as músicas foram tocadas "É preciso saber viver" e músicas religiosas que tratavam sobre perseverança e Jesus, dentre elas "Noites Traiçoeiras": "E ainda se vier noites traiçoeiras, se a cruz pesada for, Cristo estará contigo..."

\section{Dor/Sofrimento/Morte}

\section{POLÊM!CA $\mid$ LABORE}


O assunto do diagnóstico do câncer apareceu inicialmente com o impacto emocional e em sua associação com a morte. No entanto, as pacientes expressam a transformação da expectativa única da morte, do fim, para a da possibilidade de recuperação, quando passam a ter informações, ao ver exemplos de outras pacientes e a fazer os tratamentos.

Dor e sofrimento foram observados na Central de Quimioterapia e explicitados quando as pacientes se referiam ao tratamento quimioterápico. A dor e o sofrimento podem se apresentar antes do início do tratamento. A presença pela primeira vez no salão de aplicação para realizar o tratamento quimioterápico estabelece o encontro das expectativas acerca do desconhecido com a vivência prática da infusão dos medicamentos. Houve pacientes que apresentaram ansiedade e medo, com alterações no corpo: "estava sentindo frio, calor" (antes de começar), outras com a tensão que aparece com a atenção ao que é feito e com o silêncio antes da punção, e na emoção, com choro.

A partir do momento em que as pacientes iniciam o tratamento, elas se expressam não mais baseadas nas expectativas, mas em suas vivências com a ação do medicamento em seus corpos, com os procedimentos técnicos e com o fato de precisarem estar ali tratando um câncer.

Elas podem expressar seus julgamentos sobre o tratamento e sobre os efeitos dos medicamentos em seus corpos:

\footnotetext{
Paciente 4: "Não é moleza não." [Acerca do tratamento. Falou mais de uma vez.]

[Paciente 1 tem uma reação ao medicamento ao final de sua aplicação:]

Paciente 1: "É forte, né?" (...) "É, o bagulho é doido."

Paciente 2: "Primeira vez?"

Paciente 1: "Sim."

Paciente 2: "Melhorou?"

Paciente 1: "Sim. Estava ardendo o nariz." [Sacudindo as pernas]. "Dá nervoso" [olhando pra mim]. (Diário de campo).
}

Referem-se ainda aos aspectos técnicos, especificamente sobre a agulha da punção, o pavor que uma paciente expressa com o fato dela poder se desencaixar e outra que considera a punção como a pior parte dos procedimentos.

Os indícios de dor e sofrimento foram interpretados também a partir de expressões corporais observadas no salão de aplicação dos quimioterápicos. Algumas expressões foram acompanhadas de falas e outras não. São elas: tristeza, medo/dor, surpresa/espanto e impaciência.

\section{POLÊM!CA $\mid$ LABORE}


A tristeza se manifestou em diferentes situações e formas de expressão: com choro e feição triste quando iria começar a aplicação (por exemplo, de uma paciente de primeira vez no tratamento para metástase, que tentava focar na leitura de um livro) ou porque passava por uma situação difícil com o tratamento; com o espanto, seguido de silêncio, expressão triste e pensativa quando uma paciente relatou a outras duas que o tratamento quimioterápico que estava fazendo era diferente do delas porque tinha sido diagnosticado metástase; com a fala "Viajar aqui no livro pra não sofrer", durante a infusão.

As expressões de medo e de dor foram observadas durante o procedimento de punção da veia: elas fecham os olhos, franzem o rosto, viram o rosto ou observam atentamente o profissional da enfermagem "furar" a veia. As expressões de espanto e surpresa, por sua vez, surgiram diante do anúncio de pacientes para outras que estavam com metástase, com a rotina diferente do protocolo (aplicação semanal) e com a descrição de sintomas que a metástase provocava. A surpresa com a condição de uma paciente morar em outro estado e vir ao Rio de Janeiro para o tratamento ou pelo questionamento de uma paciente sobre as etapas do tratamento que outra já tinha realizado.

A impaciência na expressão do corpo surgiu com o levantar de olhos de uma paciente após dizer que ia todos os dias ao hospital para o tratamento radioterápico, durante 25 dias, e a impaciência com o tempo em que se transcorrem as infusões.

Algumas pacientes demonstraram a dificuldade que é passar as horas paradas, sentadas e com limitação dos movimentos do braço puncionado durante a infusão. Observam os frascos com os remédios para verificarem se está acabando, relatam querer ir embora, mas ter que aguardar ainda todo o procedimento. Expressam a sensação de estarem presas e o alívio e a vibração quando termina a aplicação.

Outro tema que surgiu durante o período do tratamento foi a relação com a perda do cabelo. A perda do cabelo, o uso ou não de peruca ou de lenço foi um assunto que surgiu de forma espontânea nas conversas das pacientes. Algumas demonstram o sofrimento que é perder o cabelo, de forma direta: "doeu, doeu muito" (quando cortou o cabelo), ou na forma de sentimento de obrigação em ter que encarar a situação: “caiu tudo e tem que lidar, né?”. O significado atribuído por outra paciente é com a perda da autoestima: "Só de perder o cabelo a autoestima baixa pra caramba".

\section{POLÊM!CA $\mid$ LABORE}


A dor da perda do cabelo para uma paciente é ressaltada em sua fala com a descrição de como era o seu cabelo, tamanho e forma ao mostrar uma foto para as outras pacientes e com o fato de ter guardado o cabelo cortado. A exposição da careca pode ser vivida com vergonha - como declararam duas pacientes que não andam na rua sem a peruca. No entanto, o uso da peruca como artifício para esconder o que se apresenta de diferente, pode ele próprio chamar a atenção e denunciar a diferença existente. Um exemplo foi um menino apontar para a paciente na rua e declarar que ela estava usando peruca, o que foi sentido como uma ofensa. Por outro lado, tem paciente que declara não se importar com a exposição da careca, que faz uso das opções de peruca, lenço ou careca e utiliza do lúdico para lidar com a situação.

Diante dos aspectos de dor e do sofrimento durante o tratamento, as pacientes apresentaram recursos para lidar com o sofrimento. Foram identificadas três formas de recursos: com a leitura de livros durante a aplicação dos quimioterápicos ("Viajar aqui no livro para não sofrer", disse uma paciente); com a fé e a esperança - a fé foi demonstrada por meio da oração durante a infusão, com fala de incentivo de uma paciente na crença sobre a cura, com a oferta por uma paciente de óleo para unção a todos que estavam na sala de espera; e a esperança, na crença de que nada é impossível se seguir corretamente o tratamento mesmo diante de metástase -; e com a resignação. A resignação se expressa no contraste entre o que se sente e o que se precisa fazer. As pacientes e acompanhantes compensam a insatisfação que têm com a rotina de ir ao hospital e com o tempo de espera para atendimento para aplicação, com a certeza de que, apesar disso, têm a garantia da realização do tratamento.

\section{Considerações finais}

O contexto de uma doença e de seus tratamentos e a presença constante no espaço hospitalar configuram um ambiente exemplo da convivência e o perpasse entre o universo reificado, aquele em que o saber é produzido por meio da lógica e dos métodos científicos, e o universo do senso comum, em que o saber segue uma "lógica natural" e se produz nas interações cotidianas. É o contexto em que as mulheres em tratamento para o câncer de mama no HCIII estão inseridas: frequência constante no ambiente hospitalar para acompanhamento e tratamentos, contato com profissionais de diversas áreas de saber, interações com acompanhantes e outras mulheres com o câncer de mama.

\section{POLÊM!CA $\mid$ LABORE}


As mulheres e os acompanhantes passam a receber diversas informações do universo reificado: sobre a doença e sobre os tratamentos e seus possíveis efeitos colaterais, orientações do que podem ou não fazer e do que devem ou não fazer. É o exemplo das informações expostas com as observações na Central de Quimioterapia sobre o tratamento quimioterápico. Seus corpos, comportamentos e emoções ficam sob o olhar e controle do saber das ciências.

No entanto, segundo Moscovici (1978) os sujeitos não são meros receptores e repetidores daquilo que os atingem como estímulos. Eles são ativos e criativos na construção do senso comum e utilizam-se da ancoragem para aproximarem as ideias estranhas aos conhecimentos pré-existentes. Fazem isso por meio da classificação do que é novo dentro de categorias já estabelecidas, aproximando ou não dessas classificações e por meio da denominação, conferem-lhe um nome, retirando-lhe do anonimato. Paralelo a isso, associam o conjunto dessas ideias estranhas classificadas e denominadas a um complexo de imagens de forma a tornar concreto e tangível o que era abstrato - ocorre a objetivação. Transfere para o nível da observação o que estava somente a nível de organização de ideias.

Esses dois processos, ancoragem e objetivação, são o que promovem a finalidade das representações sociais: tornar o que era não familiar em familiar. Aquilo que se apresenta como novo, não reconhecível e, portanto, assustador, em algo de que se pode aproximar. Nesse percurso, há seleção das informações novas que serão utilizadas e em seguida reorganizadas.

Assim, o que foi descrito sobre a observação realizada na Central de Quimioterapia faz relação com a transformação do que não é familiar, as informações técnicas que as mulheres recebem ao longo dos tratamentos, em algo familiar. Essa familiaridade, no contexto do tratamento para o câncer, pode se dar com a apropriação que elas fazem dos aspectos técnicos: descrevem a duração e a quantidade das aplicações dos remédios, utilizam-se de termos técnicos como imunidade, orientam umas às outras sobre cuidados com o corpo durante o tratamento quimioterápico e confirmam entre si as manifestações de efeitos colaterais dos quimioterápicos.

Essa apropriação ocorre com algumas modificações como, por exemplo, adaptações das orientações do que se pode ou não se alimentar. Podem trazer para suas interações o linguajar técnico de modo a se afastarem um pouco da carga afetiva da condição de

\section{POLÊM!CA $\mid$ LABORE}


adoecimento e interferência do tratamento sobre o corpo. Ao mesmo tempo deixam de ter a intermediação do profissional detentor do saber científico para se apoderarem de algo que acontece nos próprios corpos e assim manterem um mínimo de controle sobre algo (tratamento ou doença) que causa descontroles nas funções do organismo.

Uma outra forma observada de familiarização é a nomeação dos quimioterápicos da neoadjuvancia e da adjuvância como a quimioterapia "vermelha" e a quimioterapia "branca". Um exemplo de objetivação do complexo de informação sobre esses remédios. Se enxuga o excesso dessas informações, que são os números de ciclos e os nomes dos remédios, e as materializa por meio de nomeações por cores. Pode-se falar, então, do tratamento quimioterápico como aquele dividido entre a quimioterapia vermelha e a branca, e em cada uma delas se explicar as características de efeitos colaterais vivenciados. Com isso, distanciase de um grupo complexo de significações, trazendo para perto como algo mais concreto, o que se visualiza no frasco e o que se sente no organismo. Esses processos de familiarização são como estratégias para essas mulheres lidarem com algo considerado tão ameaçador como o câncer e o tratamento quimioterápico, que podem estabelecer descontinuidades da rotina, das relações sociais e da própria existência.

\section{Referências}

ARÁN et al. Representações de pacientes mastectomizadas sobre doença e mutilação e seu impacto no diagnóstico precoce do câncer de mama. Jornal Brasileiro de Psiquiatria, v.45, n.11, p.633-639, 1996.

BARDIN, L. L'analyse de contenu et de la forme des communications. In: MOSCOVICI, S.; BUSCHINI, F. (Org.).Les méthodes des sciences humaines. Paris: PUF, 2003. p. 243-270.

BONASSA, E.M.A.; GATO, M.I.R. (Ed.) Terapêutica oncológica para enfermeiros e farmacêuticos. 4. ed. São Paulo: Editora Atheneu, 2012. 650 p.

BRASIL. Manual de Bases Técnicas da Oncologia - Sia/Sus - Sistema de Informações Ambulatoriais. Brasília, 2011a. 110 p. Disponível em:

〈http://www1.inca.gov.br/inca/Arquivos/manual_oncologia_13edicao_agosto_2011.pdf $>$. Acesso em: 27 set. 2012.

BRASIL. Ministério da Saúde. Plano de ações estratégicas para o enfrentamento das doenças crônicas não transmissíveis (DCNT) no Brasil 2011-2022. Brasília, 2011b.148p. Disponível em: <http://portal.saude.gov.br/portal/arquivos/pdf/cartilha_plano_final_11.pdf >. Acesso em: 10 out. 2011.

CONCEIÇÃO, L.L.; LOPES, R.L.M. O cotidiano de mulheres mastectomizadas: do diagnóstico à quimioterapia. Revista Enfermagem UERJ, v.16, n.1, p.26-31, 2008.

FERREIRA, C.B.; ALMEIDA, A.M.; RASERA, E.F. Sentidos do diagnóstico por câncer de mama feminino para casais que o vivenciaram. Comunicação, Saúde e Educação, v.12, n.27, p.863-871, 2008.

\section{POLÊM!CA $\mid$ LABORE}


FUNGHETTO, S.S.; TERRA, M.G.; WOLFF, L.R. Mulher portadora de câncer de mama: percepção sobre a doença, família e sociedade. Revista Brasileira de Enfermagem, v.56, n.5, p.528-532, 2003.

INSTITUTO NACIONAL DE CÂNCER JOSÉ ALENCAR GOMES DA SILVA (INCA). Estimativa 2016: incidência de câncer no Brasil. Rio de Janeiro, 2015. 122p. Disponível em:

<http://www.inca.gov.br/estimativa/2016/estimativa-2016-v11.pdf>. Acesso em: 18 fev. 2016.

Quimioterapia - Orientações aos pacientes. 3. ed. Rio de Janeiro, 2013. 16 p.

Ações de enfermagem para o controle do câncer: uma proposta de integração ensino-serviço. Rio de Janeiro, 2008. 628 p. Disponível em: <http://www.inca.gov.br/enfermagem/>. Acesso em: 26 fev. 2017.

MALINOWSKI, B. Introdução: Tema, método e objetivo desta pesquisa. In: MALINOWSKI, B. Argonautas do Pacífico Ocidental. São Paulo: Abril Cultural, 1976. p.21-38. (Os Pensadores, 43).

MOSCOVICI, S. Representações sociais: investigações em psicologia social. 5. ed. Petrópolis: Vozes, 2007. $404 \mathrm{p}$.

A representação social da psicanálise. Rio de Janeiro: Zahar, 1978. 291 p.

MISTURA, C.; CARVALHO, M. F. A. A.; SANTOS, V. E. P. Mulheres mastectomizadas: vivências frente ao câncer de mama. Revista de Enfermagem da UFSM, v.1, n.3, p.351-359, 2011.

SALES, C.A. et al. A existencialidade da pessoa com neoplasia em tratamento Quimioterápico. Acta Scientiarum. Health Sciences, v.25, n.2, p.177-182, 2003.

SOCIEDADE BRASILEIRA DE ONCOLOGIA CLÍNICA (SBOC). Manual de Condutas 2011. Revista da Sociedade Brasileira de Oncologia Clínica, 2011.

SOUZA, M.G.G; GOMES, A.M.T. Sentimentos compartilhados por familiares de pacientes oncológicos em tratamento quimioterápico: um estudo de representações sociais. Revista Enfermagem UERJ, v. 20, n.2, p.149$54,2012$.

SOUZA, M.G.G.; SANTO, F.H.E.; O olhar que olha o outro... um estudo com familiares de pessoas em quimioterapia antineoplásica. Revista Brasileira de Cancerologia, v.54, n.1, p. 31-41, 2008.

TAVARES, J.S.C.; TRAD, L.A.B. Metáforas e significados do câncer de mama na perspectiva de cinco famílias afetadas. Cadernos de Saúde Pública, v.21, n.2, p.426-435, 2005.

ZAGO, E.A.; MONTES, R.M. Processo quimioterápico em mulheres com câncer de mama: compreendendo o significado e as vivências subjetivas. Revista Brasileira de Oncologia Clínica, v. 2, n.6, p.15-24, 2005.

Recebido em: 20/02/2017.

Aceito em: 30/03/2017.

\section{POLÊM!CA $\mid$ LABORE}

Polêmica - Revista Eletrônica da Uerj - Rua São Francisco Xavier, 524, $1^{\circ}$ andar

bloco D, sl.1001 • Tels.: +55 21 2334-4088/4087 • http://www.e-publicacoes.uerj.br/index.php/polemica/index

http://www.labore.uerj.br • laboreuerj@yahoo.com.br 